\title{
Green Consumers Behavior: Perilaku Konsumen dalam Pembelian Produk Ramah Lingkungan
}

\author{
Kristiana Sri Utami \\ Manajemen, Universitas Widya Mataram, Indonesia \\ Korespondensi penulis: utamisiswaya@yahoo.com
}

\begin{abstract}
The government's concern in solving environmental problems is manifested by the launching of an environmental development program. The success of this program is highly influenced by people's behavior in choosing and consuming environmentally friendly products (also known as green consumers' behavior). This study aims to examine the effects of environmental knowledge, environment attitude, recycle behavior, and political action on green consumers' behavior in Yogyakarta Special Province, Indonesia by using a quantitative descriptive analysis of a sample of 100 respondents who were randomly selected. The type of data used in this research is primary data. The research variables consist of a dependent variable, namely green consumers' behavior $(G C B)$, and independent variables, namely environmental knowledge, environment attitude, recycle behavior, and political action. The data is processed and analyzed using the Statistical Package for the Social Sciences (SPSS) version 24. The method of this analysis used multiple linear regression. The analysis results showed that the environmental knowledge and environment attitudes have not significant effects on green consumers' behavior. While recycling behavior and political action have positive and significant effects on green consumers' behavior.
\end{abstract}

Keywords: Environmental knowledge; Environment attitude; Green consumers' behavior; Recycle behavior; Political action.

\begin{abstract}
Abstrak. Keseriusan pemerintah dalam mengatasi masalah lingkungan diwujudkan dengan dicanangkannya program pembangunan berwawasan lingkungan. Keberhasilan program ini sangat dipengaruhi oleh perilaku masyarakat dalam memilih dan mengonsumsi produk yang ramah lingkungan (atau yang dikenal dengan istilah green consumers' behavior). Penelitian ini bertujuan untuk menguji pengaruh environtmental knowledge, environtment attitude, recycle behavior, dan political action terhadap green consumers' behavior di Daerah Istimewa Yogyakarta dengan menggunakan analisis diskriptif kuantitatif terhadap sampel berjumlah 100 responden yang dipilih secara acak. Data yang dikumpulkan dan diolah merupakan data primer. Variabel penelitian terdiri atas variabel terikat, yaitu green consumers' behavior (GCB) dan variabel bebas yang terdiri atas environmental knowledge, environment attitude, recycle behavior, dan political actions. Data dianalisis menggunakan program Statistical Package for the Social Sciences (SPSS) versi 24. Metode analisis yang digunakan dalam penelitian ini adalah regresi linear berganda. Hasil analisis menunjukkan bahwa environmental knowledge
\end{abstract}


dan environment attitude tidak berpengaruh signifikan terhadap green consumers' behavior, sedangkan recycle behavior dan political action berpengaruh positif dan signifikan terhadap green consumers behavior.

Kata kunci: Perilaku daur ulang; Perilaku konsumen hijau; Pengetahuan lingkungan; Sikap terhadap lingkungan; Tindakan politik.

Article Info:

Received: August 1, $2019 \quad$ Accepted: March 18, $2020 \quad$ Available Online: March 25, 2020

DOI: http://dx.doi.org/10.30588/jmp.v9i2.499

\section{LATAR BELAKANG}

Secara global, ilmu pengetahuan dan teknologi telah meningkatkan kualitas hidup manusia. Gaya hidup masyarakat industri ditandai oleh pemakaian produk berbasis bahan kimia yang telah meningkatkan produksi limbah berbahaya bagi lingkungan hidup. Lingkungan hidup adalah kesatuan ruang dengan semua benda, daya, keadaaan, dan makhluk hidup, termasuk manusia dan perilakunya, yang mempengaruhi alam itu sendiri, kelangsungan perikehidupan, dan kesejahteraan manusia, serta makhluk hidup lain (Otoritas Jasa Keuangan, 2016). Perlindungan dan pengelolaan lingkungan hidup adalah upaya sistematis dan terpadu yang dilakukan untuk melestarikan fungsi lingkungan hidup dan mencegah terjadinya pencemaran dan/atau kerusakan lingkungan hidup yang meliputi perencanaan, pemanfaatan, pengendalian, pemeliharaan, pengawasan, dan penegakan hukum untuk mewujudkan pembangunan berkelanjutan (Otoritas Jasa Keuangan, 2016).

Saat ini, pelestarian lingkungan menjadi prioritas berbagai negara di dunia, termasuk Indonesia. Keseriusan pemerintah Indonesia akan hal tersebut diwujudkan dengan dicanangkannya program pembangunan berkelanjutan. Pembangunan berkelanjutan adalah upaya sadar dan terencana yang memadukan aspek lingkungan hidup, sosial, dan ekonomi ke dalam strategi pembangunan untuk menjamin keutuhan lingkungan hidup, serta keselamatan, kemampuan, kesejahteraan, dan mutu hidup generasi masa kini dan generasi masa depan (Otoritas Jasa Keuangan, 2016). Program tersebut merupakan upaya untuk meningkatkan kualitas hidup masyarakat dengan tetap memperhatikan kelestarian lingkungan. Pembangunan berkelanjutan dapat berhasil dengan dukungan seluruh komponen masyarakat. Upaya yang telah dilakukan oleh pemerintah dan masyarakat, antara lain: Kementerian Pekerjaan Umum dan Perumahan Rakyat (KemenPUPR) melakukan program pemeringkatan jalan hijau. Pemeringkatan jalan bertujuan untuk mendorong pembangunan jalan yang berkelanjutan dengan menggunakan sumber daya seefisien mungkin dan berwawasan lingkungan (Kencana, 2018). Program Revitalisasi Gerakan Nasional-Kemitraan Penyelamatan Air yang disepakati tanggal 9 Mei 2015 oleh delapan kementerian, yaitu Kementerian Dalam Negeri, Kementerian Perencanaan Pembangunan Nasional/Bappenas, Kementerian Pekerjaan Umum dan Perumahan Rakyat, Kementerian Pertanian, Kementerian Lingkungan Hidup dan Kehutanan, Kementerian Badan Usaha Milik Negara, Kementerian Agraria dan Tata Ruang/Badan Pertanahan Nasional, dan Kementerian Desa, Pembangunan Daerah Tertinggal, dan Transmigrasi, bertujuan untuk mengembalikan keseimbangan siklus hidrologi pada Daerah Aliran Sungai (DAS) dicapai melalui program pemerintah 
pusat dan daerah, pelibatan dunia usaha, dan peran serta masyarakat (Kementerian PUPR, 2015).

Dalam sektor usaha, upaya menjaga kelestarian lingkungan diwujudkan dengan implementasi go green pada berbagai bidang, yaitu pemasaran, produksi, maupun keuangan. Dari sektor rumah tangga, konsumen dikenal dengan istilah green consumers. Green consumers atau konsumen hijau didefinisikan sebagai individu yang melakukan pembelian dengan terlebih dahulu memikirkan dampak terhadap lingkungan dari barang yang mereka konsumsi (Irawan \& Vianney, 2015). Ketika dihadapkan kepada alternatif antara dua produk, konsumen hijau akan lebih memilih produk yang lebih ramah lingkungan (Baker \& Ozaki, 2008). Perilaku konsumen yang peduli terhadap lingkungan akan termotivasi untuk mengonsumsi produk yang ramah lingkungan (Andrew \& Slamet, 2013). Perilaku yang didasarkan pada kepedulian terhadap lingkungan atau green consumers' behavior dicerminkan oleh perilaku individu saat mencari, membeli, menggunakan, mengevaluasi, dan membuang produk (Siringi, 2012), sedangkan keputusan pembelian produk oleh konsumen seringkali didasarkan pada sikap mereka terhadap lingkungan (environment attitude) (Irland, 1993). Sikap merupakan salah satu faktor yang mempengaruhi kualitas lingkungan (Mansaray \& Ajiboye, 1998), dan menjadi faktor penjelas paling konsisten dalam memprediksi kesediaan konsumen untuk membayar produk ramah lingkungan (Tsen, Phang, Hasan, \& Buncha, 2006).

Permasalahan lingkungan tidak hanya dihadapi di Indonesia, tetapi hal itu telah menjadi perhatian masyarakat dunia sejak beberapa tahun lalu terutama yang terkait dengan limbah padat. Di Indonesia sendiri, sebagai negara dengan garis pantai sepanjang 99.093 kilometer dengan populasi 255.460.000 orang, merupakan penghasil sampah plastik terbesar kedua di dunia setelah China (Widadio, 2019). Produksi sampah Indonesia mencapai 66-67 juta ton sampah pada tahun 2019, jumlah ini lebih tinggi dibandingkan jumlah sampah per tahun yang mencapai 64 juta ton pada tahun 2018. Dari jumlah tersebut 3,2 juta ton merupakan sampah plastik dan 1,3 juta ton berakhir terbuang di laut (Permana, 2019). Lembaga Ilmu Pengetahuan Indonesia (LIPI) mencatat 0,27 juta ton hingga 0,9 juta ton sampah yang masuk ke laut per tahun melewati aliran-aliran sungai, sedangkan sampah yang paling dominan adalah sampah plastik sekali pakai, seperti styrofoam dan lembaran plastik (Widadio, 2019)

Rufinaldo (2019) menuliskan bahwa upaya mengurangi dampak lingkungan dari limbah padat dapat dilakukan dengan minimalisasi penggunaan plastik, seperti kesepakatan yang dilakukan oleh negara-negara Uni Eropa (UE) pada bulan Desember 2019, yaitu pembatasan pada produk plastik sekali pakai dalam upaya untuk mengurangi sampah di laut dan darat bagi negara-negara anggotanya. Piring plastik, peralatan makan, sedotan, tongkat balon, dan korek kuping sekali pakai dilarang mulai tahun 2021. Negara-negara anggota UE juga menyepakati untuk mencapai target pengumpulan botol plastik 90 persen pada tahun 2029. Botol plastik harus mengandung setidaknya 25 persen kandungan yang dapat didaur ulang pada tahun 2025 dan 30 persen pada tahun 2030.

Kerusakan lingkungan juga disebabkan adanya pertumbuhan ekonomi yang cepat dan mendorong terjadinya konsumsi dan eksploitasi sumber daya alam secara berlebihan. Menurunnya kualitas kehidupan sosial dan kesehatan merupakan dampak dari kerusakan lingkungan, selain dampak berupa pemanasan global, degradasi lingkungan (tanah, udara, air), serta penipisan lapisan ozon (Biswas \& Roy, 2015). Di sisi lain, masa- 
lah lingkungan memiliki keterkaitan dengan politik. Ancaman nyata bagi bumi adalah hilangnya keanekaragaman hayati dan polusi sebagai dampak dari perubahan iklim yang tidak lagi dapat diabaikan oleh pemerintah, pelaku bisnis, individu, maupun partai politik (Neil, 2018). Pengembangan gagasan hijau berupa pembuatan kebijakan publik yang terkait permasalahan lingkungan di tingkat internasional, nasional, dan lokal, keadilan iklim, dan perundang-undangan iklim merupakan bentuk aksi atau tindakan politik (political action) pro-lingkungan (Neil, 2018).

Di Indonesia, kesadaran terhadap lingkungan semakin meningkat. Hal tersebut dapat dilihat dari tumbuhnya gerakan, seperti hari bumi (earth day), pergi bekerja menggunakan sepeda (bike to work), hari bebas kendaraan (car free day), dan beberapa gerakan yang mendukung kegiatan pelestarian lingkungan maupun gerakan gaya hidup lebih sehat (Adialita, 2015). Dukungan pendidikan terhadap kelestarian lingkungan yang semakin membaik, serta meningkatnya daya beli masyarakat menjadikan Indonesia sebagai pasar potensial. Namun, meskipun Indonesia memiliki potensi yang besar, informasi mengenai perilaku konsumen hijau (green consumer behavior) masih relatif lebih sedikit dibandingkan dengan di negara-negara maju yang sudah lebih dulu memulai gerakan peduli lingkungan (Lee, 2014).

Uraian latar belakang tersebut mengindikasikan adanya keterkaitan antara perilaku konsumen hijau, pengetahuan, sikap, perilaku daur ulang, dan aksi politik. Secara khusus, penelitian ini bertujuan untuk menguji pengaruh pengetahuan lingkungan (environtmental knowledge), sikap terhadap lingkungan (environtment attitude), perilaku mendaur ulang (recycle behavior), dan tindakan politik (political action) terhadap perilaku konsumen hijau (green consumers' behavior). Dalam jangka panjang, penelitian ini dapat memberikan kontribusi bagi penyelesaian permasalahan kelestarian lingkungan berdasarkan pemikiran bahwa masyarakat yang sadar terhadap perilaku pembeliannya akan mampu menjalankan perannya untuk mengatasi permasalahan lingkungan.

\section{KAJIAN TEORITIS}

\section{Green Consumers}

Pada umumnya, konsumen ramah lingkungan didefinisikan sebagai orang yang mengadopsi perilaku ramah lingkungan dan/atau yang membeli produk ramah lingkungan di atas alternatif standar (Shamdasani, Chon-Lin, \& Richmond, 1993). Seseorang yang melakukan pembelian produk dipengaruhi oleh kesadarannya sendiri terhadap masalah lingkungan (Shrum, Mccarty, \& Lowrey, 2013). Konsumen ramah lingkungan cenderung mengonsumsi produk-produk yang ramah lingkungan (Herri \& Putri, 2006). Menurut beberapa pengertian green consumer tersebut, maka konsumen hijau adalah mereka yang mempertimbangkan dampak lingkungan terlebih dahulu sebelum membeli dan mengonsumsi suatu produk.

Dalam penelitian ini, istilah "hijau" dan "ramah lingkungan" digunakan secara bergantian dengan pemahaman yang sama. Produk ramah lingkungan adalah produk yang dalam proses produksinya menggunakan teknologi produksi yang tidak mencemari lingkungan serta menggunakan bahan baku dan kemasan dari bahan yang dapat didaur ulang (Cason \& Gangadharan, 2002). Dengan demikian, produk hijau adalah produk yang dihasilkan dari proses produksi yang aman terhadap lingkungan dan memiliki dampak pemakaian yang aman terhadap lingkungan. Perilaku berwawasan lingkungan 
(environmental behavior) dipengaruhi oleh tujuh variabel (Lee, 2008), yaitu: (1) Environment attitude (sikap terhadap lingkungan) yang mengacu pada penilaian kognitif individu terhadap nilai atas perlindungan lingkungan; (2) Environmental concern (kepedulian terhadap lingkungan), yaitu tingkat keterlibatan secara emosional dalam isu-isu lingkungan; (3) Perceived seriousness of environmental problems (pemahaman mengenai keseriusan atas masalah-masalah lingkungan); (4) Perceived environmental responsibility (pemahaman mengenai tanggung jawab lingkungan); (5) Perceived effectiveness of environmental behavior (pemahaman mengenai keefektifan perilaku lingkungan); (6) Perceived self-image in environmental protection (pemahaman mengenai self-image dalam perlindungan lingkungan); dan (7) Peer-influence (pengaruh teman sebaya).

\section{Green Consumers'Behavior}

Green consumers' behavior (GCB) adalah perilaku individu yang dipengaruhi oleh kepeduliannya terhadap lingkungan. Perilaku ini dicerminkan oleh individu, ketika ia mencari, membeli, menggunakan, mengevaluasi, dan membuang produk (Siringi, 2012). Perilaku konsumen yang peduli terhadap lingkungan akan mempengaruhi keinginannya untuk mengonsumsi produk yang ramah lingkungan (Andrew \& Slamet, 2013). Berbagai isu lingkungan mulai menjadi kekhawatiran masyarakat dunia di era tahun 90an. Di Eropa dan Amerika Serikat, perusahaan menyadari bahwa konsumen akan membeli atau tidaknya suatu produk didasarkan pada pertimbangan isu lingkungan (Andrew \& Slamet, 2013). Perilaku pembelian dapat ditemukan dalam berbagai survei. Contohnya, pada bulan Juli 1989, jajak pendapat MORI (Market and Opinion Research International) menunjukkan bahwa proporsi konsumen memilih produk atas dasar kinerja lingkungan telah meningkat dari $19 \%$ menjadi $42 \%$ dalam waktu kurang dari satu tahun (H'Mida, Chavez, \& Guindon, 2008).

Kesadaran lingkungan diartikan sebagai konstruksi multidimensi, yang terdiri atas kognitif, sikap, dan komponen perilaku (Tantawi, Shaughnessy, Gad, \& Ragheb, 2009). Konsumen dengan tingkat kesadaran lingkungan yang tinggi membuat keputusan pembelian produk ramah lingkungan meningkat dibandingkan produk yang kurang memperhatikan isu lingkungan. Dengan demikian, ukuran kesadaran lingkungan akan lebih erat kaitannya dengan kebiasaan pembelian daripada sosiodemografi atau variabel kepribadian (Chan, Wong, \& Leung, 2008). Untuk melihat tingkat kesadaran konsumen atas kelestarian lingkungan, perilaku pembelian mereka terhadap produk ramah lingkungan dapat menjelaskannya. Menurut Jati dan Waluyo (2012), empat variabel dapat mempengaruhi perilaku pembelian konsumen, yaitu environtmental knowledge, environtment attitude, recycling behavior, dan political action (Jati \& Waluyo, 2012).

\section{Environmental Knowledge (Pengetahuan terhadap Lingkungan)}

Wawasan dan pengetahuan konsumen menjadi faktor penting bagi upaya melakukan go green di Indonesia. Secara umum, pengetahuan masyarakat untuk menjaga kelestarian lingkungan masih relatif rendah sehingga perlu mendapatkan perhatian serius (Jati \& Waluyo, 2012). Rendahnya wawasan dan pengetahuan konsumen tentang lingkungan berdampak pada aktifitas green marketing (pemasaran berwawasan lingkungan) yang masih sedikit dan perilaku konsumen yang pro-lingkungan masih relatif rendah di Indonesia (Adialita, 2015).

Kesadaran konsumen akan timbul dan semakin kuat, jika mereka diberikan informasi dan pengetahuan yang lengkap dan akurat tentang isu lingkungan. Pengetahuan konsumen yang baik akan mendorong perilaku positif terhadap keberlangsungan ling- 
kungan. Semakin tinggi tingkat pengetahuan masyarakat terhadap lingkungan akan semakin meningkatkan kesadaran untuk membeli produk ramah lingkungan (Jati \& Waluyo, 2012). Oleh karena itu, produsen perlu menerapkan strategi, di antaranya menciptakan dan menggunakan komponen ramah lingkungan, mencantumkan label ramah lingkungan (eco-labelling) untuk melakukan standarisasi produk, sertifikasi, serta mengomunikasikan bahwa produk yang mereka tawarkan masuk ke dalam klasifikasi produk ramah lingkungan (Septifani, Achmadi, \& Santoso, 2014). Berdasarkan uraian tersebut, maka hipotesis kesatu penelitian ini dirumuskan sebagai berikut:

\section{H1: Pengetahuan terhadap lingkungan (environmental knowledge) berpengaruh signifikan terhadap green consumers' behavior.}

\section{Environment Attitude (Sikap terhadap Lingkungan)}

Sikap merupakan bentuk evaluasi perasaan dan kecenderungan potensial untuk bereaksi yang merupakan hasil interaksi antara komponen kognitif, afektif, dan konatif (Azwar, 2010). Sikap dan perilaku seseorang dalam mengambil keputusan terhadap lingkungan menjadi salah satu faktor dalam usaha meningkatkan kualitas lingkungan. Hal ini dapat diartikan bahwa kepedulian lingkungan berhubungan secara positif dengan sikap (Jekria \& Daud, 2016). Menurut Lee (2008), tujuh variabel mempengaruhi perilaku pro-lingkungan seseorang, salah satunya adalah environment attitude yang mengacu pada penilaian kognitif individu terhadap nilai perlindungan lingkungan. Sikap terhadap lingkungan mengacu pada pertimbangan nilai individu terhadap perlindungan lingkungan. Berdasarkan paparan tersebut, maka hipotesis kedua dalam penelitian ini dirumuskan sebagai berikut:

\section{H2: Sikap terhadap lingkungan (environment attitude) berpengaruh secara signifi- kan terhadap green consumers'behavior.}

\section{Recycle Behavior (Perilaku Daur Ulang)}

Untuk meningkatkan kepedulian masyarakat terhadap keberlanjutan lingkungan dapat dilakukan melalui sosialisasi secara berkesinambungan tentang akibat yang ditimbulkan dari perilaku yang mengabaikan lingkungannya. Recycle (daur ulang) adalah proses untuk menjadikan suatu barang bekas menjadi barang baru dengan tujuan mencegah adanya sampah berserakan (Rijati, Intan, \& Subekti, 2017). Daur ulang merupakan salah satu strategi pengelolaan sampah padat yang terdiri atas kegiatan pemilahan sampah yang dapat didaur ulang, pengumpulan, pemrosesan lebih lanjut, pendistribusian, dan pembuatan produk/material bekas pakai, serta komponen utama (Rijati et al., 2017). Hal ini merupakan bagian dari proses hierarki penanggulangan sampah 4R (Reduce, Reuse, Recycle, and Replace) (Colin, Hammond, Lamond, \& Proverbs, 2012).

Dengan demikian, recycle behavior adalah perilaku individu yang dipengaruhi oleh kepeduliannya terhadap lingkungan, yang dicerminkan oleh cara individu tersebut mencegah adanya sampah melalui pengelolaan sampah padat. Sebuah program daur ulang hanya akan berhasil, jika masyarakat mendukung secara aktif dengan ikut berpartisipasi di dalamnya. Hal ini sejalan dengan hasil penelitian sebelumnya yang menyatakan bahwa terdapat hubungan positif antara kepedulian terhadap lingkungan dan perilaku mendaur ulang (Schultz, Oskamp, \& Mainieri, 1995). Kondisi tersebut menunjukkan 
bahwa kepedulian lingkungan merupakan variabel potensial yang dapat mempengaruhi keputusan konsumen untuk mendaur ulang (Jekria \& Daud, 2016). Berdasarkan penjelasan tersebut, maka hipotesis ketiga penelitian ini dirumuskan sebagai berikut:

\section{H3: Perilaku daur ulang (recycle behavior) oleh konsumen berpengaruh signifikan terhadap green consumers' behavior.}

\section{Political Action (Tindakan Politik)}

Setiap individu membutuhkan lingkungan sebagai pemenuhan kebutuhan hari ini dan ruang pemenuhan kebutuhannya di masa depan. Lingkungan dapat berfungsi sebagai basis pertama dan utama dalam pengaturan politik masa kini dan masa depan (Lay, 2007). Pertumbuhan ekonomi yang cepat mendorong terjadinya konsumsi dan sekaligus ekploitasi sumber daya alam secara berlebihan, sehingga kondisi tersebut berdampak pada terjadinya kerusakan lingkungan berupa penipisan lapisan ozon, pemanasan global, penurunan kualitas kehidupan, dan degradasi lingkungan (Biswas \& Roy, 2015). Sebagian dari tindakan politik terjadi karena dipicu oleh permasalahan lingkungan. Polusi, hilangnya aneka ragam hayati, dan perubahan iklim merupakan ancaman nyata bagi kehidupan masyarakat yang tidak dapat diabaikan, baik oleh pemerintah, pelaku bisnis, individu, maupun partai politik (Neil, 2018).

Aksi-aksi atau tindakan politik pro-lingkungan dibutuhkan untuk mendorong perilaku yang dapat meminimalkan dampak kerusakan lingkungan. Aksi-aksi politik (political action) tersebut dilakukan melalui pengembangan gagasan hijau, pembuatan kebijakan publik yang pro-lingkungan di tingkat internasional, nasional, dan lokal, keadilan iklim, dan perundang-undangan tentang iklim yang sangat diperlukan (Neil, 2018). Strategi dan aksi-aksi politik tersebut memberikan pengaruh terhadap lahirnya regulasi, memperkuat penegakan hukum khususnya terkait lingkungan, mempengaruhi banyak sektor kehidupan, dan mendorong tumbuhnya praktik-praktik pengelolaan lingkungan (Ardhian, Adiwibowo, \& Wahyuni, 2016). Aksi politik dalam penelitian ini merupakan tindakan atau kegiatan bermotivasi politik yang diarahkan bagi upaya kelestarian lingkungan. Berdasarkan paparan tersebut, maka rumusan hipotesis keempat dalam penelitian ini dirumuskan sebagai berikut:

\section{H4: Tindakan politik (political action) berpengaruh secara signifikan terhadap green consumers' behavior.}

Berdasarkan rumusan keempat hipotesis tersebut, rerangka berpikir dalam penelitian ini ditunjukkan pada model penelitian yang ditunjukkan pada Gambar 1.

\section{METODE PENELITIAN}

\section{Jenis Penelitian, Populasi, dan Sampel}

Jenis penelitian yang digunakan pada penelitian ini adalah kuantitatif. Populasi penelitian ini adalah masyarakat (konsumen) yang berdomisili di Provinsi Daerah Istimewa Yogyakarta (DIY). Metode pengambilan sampel yang digunakan adalah nonprobability sampling dengan teknik purposive sampling. Purposive sampling adalah teknik pengambilan sampel dengan pertimbangan tertentu agar lebih representative hasilnya (Sugiyono, 2013). Pertimbangan pengambilan sampel penelitian ini adalah ma- 
syarakat yang berdomisili di wilayah Provinsi DIY, berusia lebih dari 15 tahun, dan pernah melakukan pembelian produk ramah lingkungan sebelumnya.

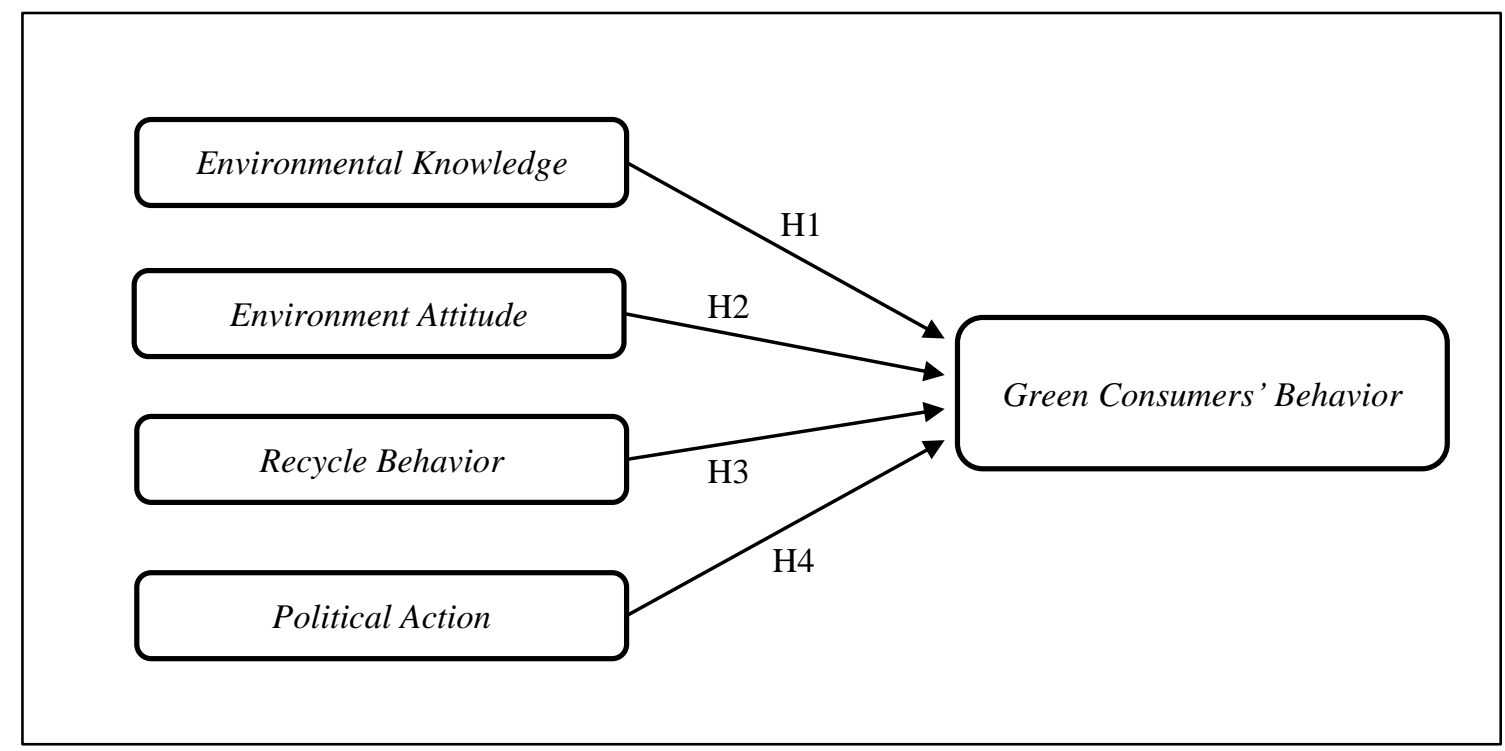

\section{Gambar 1. Model Penelitian}

\section{Jenis dan Sumber Data}

Dalam penelitian ini jenis data yang dikumpulkan, yaitu:

1. Data Primer yaitu data yang dikumpulkan secara langsung dari sumbernya. Data primer yang digunakan dalam penelitian ini adalah data hasil survei secara online (daring) melalui jejaring whattshap, facebook, dan instagram. Hal ini dengan pertimbangan adanya kemudahan dengan kemajuan teknologi informasi. Tersedianya akses internet memudahkan peneliti untuk mengatasi kendala-kendala yang dihadapi dalam penelitian konvensional (offline) (Setiawan, 2012). Kemudahan tersebut antara lain penghematan biaya dan waktu, jangkauan penelitian lebih luas sejauh lokasi tersebut memiliki akses internet, memungkinkan jumlah responden dalam jumlah besar, serta kemampuan akses melalui berbagai media penyebaran, seperti komputer desktop, netbook, smartphone, tablet, maupun handphone (Setiawan, 2012).

Dalam menyusun kuesioner peneliti menggunakan aplikasi google form melalui beberapa tahapan, yaitu menyusun kerangka survei, menyusun instrumen kuesioner, mengakses situs web google form, melakukan pengisian aplikasi dengan butir-butir instrumen yang sudah disiapkan dan kebutuhan data yang lain, menyebarkan survei online, mengunduh hasil survei, mengolah data, dan menyusun laporan. Kuesioner penelitian ini berisi butir-butir pertanyaan terkait karakteristik responden dan pengukuran variabel penelitian berdasarkan skala Likert dengan kisaran lima kategori jawaban seperti ditunjukkan pada Tabel 1.

2. Data sekunder merupakan data yang telah disusun oleh pihak lain dalam bentuk artikel jurnal, buku, dan laporan-laporan (Sugiyono, 2013). Data sekunder yang diguna- 
kan dalam penelitian ini adalah artikel jurnal, buku, dan peraturan pemerintah yang terkait topik bahasan penelitian ini.

Tabel 1. Skala dan Pengukuran Variabel Penelitian

\begin{tabular}{|c|c|c|c|c|c|}
\hline \multirow{2}{*}{ No } & \multirow{2}{*}{ Variabel } & \multirow{2}{*}{ Jumlah Butir } & \multirow{2}{*}{ Pengukuran Variabel } & \multicolumn{2}{|c|}{ Kisaran Skala Jawaban } \\
\hline & & & & 1 & 5 \\
\hline 1 & $\begin{array}{l}\text { Green Consumers, } \\
\text { Behavior }\end{array}$ & 6 & $\begin{array}{l}\text { Perilaku sebelum membeli } \\
\text { atau mengonsumi produk. }\end{array}$ & $\begin{array}{l}\text { Tidak } \\
\text { pernah } \\
\text { melakukan }\end{array}$ & $\begin{array}{l}\text { Selalu } \\
\text { melakukan }\end{array}$ \\
\hline 2 & $\begin{array}{l}\text { Environmental } \\
\text { Knowledge }\end{array}$ & 4 & $\begin{array}{l}\text { Pengetahuan umum tentang } \\
\text { lingkungan dan } \\
\text { permasalahannya. }\end{array}$ & $\begin{array}{l}\text { Tidak tahu } \\
\text { apa-apa }\end{array}$ & $\begin{array}{l}\text { Tahu } \\
\text { banyak }\end{array}$ \\
\hline 3 & $\begin{array}{l}\text { Environment } \\
\text { Attitude }\end{array}$ & 3 & $\begin{array}{l}\text { Sikap terhadap isu-isu } \\
\text { lingkungan. }\end{array}$ & $\begin{array}{l}\text { Sangat } \\
\text { tidak setuju }\end{array}$ & $\begin{array}{l}\text { Sangat } \\
\text { setuju }\end{array}$ \\
\hline 4 & Recycle Behavior & 3 & Aktivitas mendaur ulang. & $\begin{array}{l}\text { Tidak } \\
\text { pernah }\end{array}$ & Sering \\
\hline 5 & Political Action & 3 & $\begin{array}{l}\text { Tindakan politik untuk } \\
\text { memerangi permasalahan } \\
\text { lingkungan. }\end{array}$ & $\begin{array}{l}\text { Tidak } \\
\text { pernah }\end{array}$ & Sering \\
\hline
\end{tabular}

Sumber: Bohlen, Schlegelmilch, \& Diamantopoulos (1993).

\section{HASIL DAN PEMBAHASAN}

\section{Analisis Profil Responden}

Responden dalam penelitian ini adalah warga masyaralat yang berdomisili di wilayah Provinsi DIY dan memenuhi kriteria yang sudah ditentukan dalam penelitian ini. Penyebaran kuesioner dilakukan melalui grup whatshapp (WA) maupun secara personal, dan instagram. Jumlah responden yang merespon kuesioner berjumlah 109. Setelah dilakukan evaluasi, sembilan responden di antaranya berdomisili di luar Provinsi DIY, sehingga tidak dimasukkan sebagai responden. Oleh karena itu, jumlah responden yang digunakan dalam analisis data adalah 100 orang. Jumlah responden (n) sebanyak 100 orang dalam sebuah penelitian survei dianggap layak dan memenuhi ukuran sampel (Sugiyono, 2013).

Dari pengumpulan data, responden berjenis kelamin perempuan sebanyak $48 \%$, sedangkan sisanya $52 \%$ adalah responden laki-laki. Seratus orang responden tersebut berasal dari berbagai wilayah kabupaten/kota di Provinsi DIY, yaitu Kabupaten Sleman, Kabupaten Bantul, Kabupaten Gunung Kidul, Kabupaten Kulon Progo, dan Kota Yogyakarta. Sebagian besar responden berusia antara 31-40 tahun sebanyak 32\%. Responden berusia 41-50 tahun sebesar 29\%, berusia lebih dari 50 tahun $20 \%$, berusia 2130 tahun 16\%, sedangkan persentase terendah berusia kurang dari 21 tahun, yaitu 3\%. Berdasarkan pendidikan terakhir, responden yang berpendidikan S2/S3 sebanyak 35\%, S1 mencapai 28\%, SMA/SMK sebanyak 27\%, dan Diploma sebesar 10\%. Selanjutnya, sebagian besar responden bekerja sebagai aparatur sipil negara (ASN) sebanyak 46\%, karyawan swasta $22 \%$, profesi tertentu seperti dosen/guru/hakim/jaksa/pengacara sebanyak $11 \%$, pelajar/mahasiswa $8 \%$, wirausaha $6 \%$, dan lainnya $7 \%$. 


\section{Uji Validitas}

Instrumen penelitian ini dilakukan pengujian validitas untuk mengukur seberapa besar tingkat validitas alat ukur yang digunakan. Uji validitas dilakukan terhadap 100 orang responden dengan instrumen penelitian berjumlah 19 butir pertanyaan dengan metode bivariate correlation product moment dengan bantuan program statistik SPSS 24 for windows. Dari hasil uji validitas dengan signifikansi 0,05 tersebut, seluruh butir instrumen penelitian dinyatakan valid. Analisis dengan metode bivariate correlation product moment didapatkan dari nilai korelasi antara skor butir dan skor total yang ditunjukkan pada Tabel 2. Nilai tersebut dibandingkan dengan nilai r-tabel pada taraf signifikansi 0,05 pada $(\mathrm{n})=100$, maka $r$-tabel didapatkan angka sebesar 0,1966. Berdasarkan hasil pengujian tersebut, nilai korelasi untuk semua butir lebih besar dari 0,1966, sehingga semua butir berkorelasi signifikan dengan skor total dan dinyatakan valid.

Tabel 2. Hasil Uji Validitas

\begin{tabular}{|c|c|c|c|c|c|}
\hline Butir & $\begin{array}{c}\text { Pearson } \\
\text { Correlation }\end{array}$ & Hasil & Butir & $\begin{array}{c}\text { Pearson } \\
\text { Correlation }\end{array}$ & Hasil \\
\hline GCB_1 & $.683^{* *}$ & valid & EA_2 & $.448^{* *}$ & valid \\
\hline GCB_2 & $.736^{* *}$ & valid & EA_3 & $.230^{*}$ & valid \\
\hline GCB_3 & $.626^{* *}$ & valid & EA_4 & $.614^{* *}$ & valid \\
\hline $\mathrm{GCB}$ & $.652^{\text {** }}$ & valid & $\mathrm{RB}$ & $.653^{\text {** }}$ & valid \\
\hline GCB_5 & $.645^{* *}$ & valid & RB_2 & $.779^{* * *}$ & valid \\
\hline $\mathrm{GCB} \_6$ & $.790^{* *}$ & valid & $\mathrm{RB} 33$ & $.597^{\text {*** }}$ & valid \\
\hline EK_1 & $.769^{* *}$ & valid & PA_1 & $.726^{* * *}$ & valid \\
\hline EK_2 & $.643^{* * *}$ & valid & PA_2 & $.850^{* * * * 3}$ & valid \\
\hline EK_3 & $.521^{* *}$ & valid & PA_3 & $.628^{* * *}$ & valid \\
\hline EK_4 & $.688^{* *}$ & valid & TOTAL & 1 & valid \\
\hline
\end{tabular}

Keterangan: GCB (Green Consumers' Behavior), EK (Environmental Knowledge), EA (Environment Attitude), RB (Recycle Behavior), PA (Political Action).

Sumber: Data diolah menggunakan SPSS 24,0 (2019).

\section{Uji Reliabilitas}

Uji reliabilitas dilakukan terhadap jawaban 100 responden atas 19 butir pertanyaan yang diajukan. Tabel 3 menunjukkan hasil pengujian reliabilitas dengan nilai Cronbach's alpha lebih besar dari 0,6. Hasil pengujian tersebut menggambarkan bahwa butir-butir instrumen penelitian pada setiap variabel dinyatakan reliabel.

Tabel 3. Hasil Uji Reliabilitas

\begin{tabular}{ccc}
\hline Butir & Cronbach's Alpha & Keterangan \\
\hline GCB & 0,915 & Reliabel \\
EK & 0,919 & Reliabel \\
EA & 0,920 & Reliabel \\
\hline RB & 0,918 & Reliabel \\
\hline PA & 0,921 & Reliabel \\
\hline
\end{tabular}

Keterangan: GCB (Green Consumers' Behavior), EK (Environmental Knowledge), EA (Environment Attitude), RB (Recycle Behavior), PA (Political Action).

Sumber: Data diolah menggunakan SPSS 24,0 (2019). 


\section{Analisis Regresi Linear Berganda}

Penelitian ini menggunakan model analisis regresi linier berganda. Analisis ini menggunakan input berdasarkan data yang diperoleh dari kuesioner dan menggunakan bantuan program SPSS versi 24,0. Hasil analisis regresi ditunjukkan pada Tabel 4.

Tabel 4. Hasil Analisis Regresi

\begin{tabular}{lrrrrr}
\hline \multicolumn{1}{c}{ Model } & \multicolumn{2}{c}{$\begin{array}{c}\text { Unstandardized } \\
\text { Coefficients }\end{array}$} & $\begin{array}{c}\text { Standardized } \\
\text { Coefficients }\end{array}$ & T & \multirow{2}{*}{ Sig. } \\
& B & Std. Error & Beta & & \\
\hline (Constant) & 3.374 & 4.048 & & .833 & .407 \\
Environmental Knowledge & .283 & .232 & .136 & 1.222 & .225 \\
Environment Attitude & .493 & .344 & .139 & 1.431 & .156 \\
Recycle Behavior & .445 & .205 & .254 & 2.177 & .032 \\
Political Action & .444 & .222 & .250 & 1.997 & .049 \\
\hline
\end{tabular}

Sumber: Data diolah menggunakan SPSS 24,0 (2019).

Berdasarkan hasil analisis pada Tabel 4, persamaan regresi linear berganda dalam model penelitian ini adalah:

$$
Y=3,374+0,283 X_{1}+0,493 X_{2}+0,445 X_{3}+0,444 X_{4}
$$

Keterangan:

$\mathrm{Y}$ : green consumers' behavior (perilaku konsumen hijau)

$\mathrm{X}_{1}$ : environmental knowledge (pengetahuan tentang lingkungan)

$\mathrm{X}_{2}$ : environment attitude (sikap terhadap lingkungan)

$\mathrm{X}_{3}$ : recycle behavior (perilaku daur ulang)

$\mathrm{X}_{4}$ : political action (tindakan politik)

a : konstanta (nilai Y' apabila $X_{1}, X_{2} \ldots . . X_{n}=0$ ).

Hasil tersebut menggambarkan bahwa variabel pengetahuan tentang lingkungan, sikap terhadap lingkungan, perilaku mendaur ulang, dan aksi-aksi politik berpengaruh positif terhadap green consumers behavior. Semakin tinggi pengetahuan/wawasan seseorang tentang lingkungan akan berpengaruh pada meningkatnya perilakunya pada pembelian produk ramah lingkungan. Hal itu ditunjukkan oleh nilai koefisien positif sebesar 0,283. Hasil tersebut menguatkan penelitian Adialita (2015). Kesadaran konsumen akan timbul dan semakin kuat, apabila ia diberikan informasi dan pengetahuan yang lengkap dan benar tentang isu lingkungan.

Pengetahuan konsumen yang benar akan mendorong perilaku positif terhadap keberlanjutan lingkungan (environmental sustainability). Semakin tinggi tingkat pengetahuan masyarakat terhadap lingkungan akan mendorong semakin tingginya kesadarannya untuk membeli produk yang lebih ramah lingkungan. Pengetahuan yang dimaksud tersebut adalah berbagai informasi tentang produk ramah lingkungan, isu-isu lingkungan saat ini (seperti pemanasan global, efek rumah kaca, kerusakan hutan), dampak pemakaian produk yang tidak ramah lingkungan, dan langkah-langkah yang harus dilakukan dalam perlindungan lingkungan.

Sikap seseorang pada saat mengambil keputusan terkait lingkungan akan menjadi faktor yang berpengaruh terhadap green consumers behavior. Hal ini ditunjukkan dengan nilai koefisien positif 0,493. Hasil tersebut mendukung penelitian (Lee, 2008). 
Sikap ini dapat terbentuk karena pengaruh hubungan sosial, interaksi dengan orang lain, pengalaman pribadi, media massa, maupun institusi/lembaga.

Perilaku mendaur ulang memiliki pengaruh positif (searah) terhadap green consumers behavior. Hasil analisis pada Tabel 4 dapat dilihat nilai koefisien perilaku daur ulang adalah positif 0,445 . Hal ini menguatkan hasil penelitian bahwa terdapat hubungan positif antara kepedulian terhadap lingkungan dan perilaku daur ulang (Schultz et al., 1995). Untuk meningkatkan dan memotivasi masyarakat agar memiliki perilaku daur ulang dibutuhkan upaya dalam bentuk pengelolaan program daur ulang secara terbuka, berkelanjutan, dan disosialisasikan kepada masyarakat luas melalui media massa, baik cetak maupun elektronik. Program daur ulang dapat dalam bentuk melaku-kan daur ulang produk dan menggunakannya kembali, memisahkan sampah yang dapat didaur ulang dan yang tidak, memanfaatkan barang bekas untuk kegiatan yang bernilai ekonomi

Peningkatan aksi-aksi politik akan meningkatkan green consumers' behavior. Hal ini dapat terlihat dari nilai koefisien positif 0,444. Nilai tersebut menunjukkan adanya pengaruh positif antara tindakan politik terhadap perilaku konsumen hijau. Hal ini menguatkan hasil penelitian Ardhian et al. (2016) bahwa aksi politik akan mendorong tumbuhnya praktik-praktik pengelolaan lingkungan. Aksi politik dapat dilakukan dengan membentuk forum-forum formal/non-formal. Upaya untuk meningkatkan political action dapat dilakukan dengan membentuk kelompok diskusi tentang isu-isu lingkungan, berbagi informasi dengan teman/saudara tentang produk ramah lingkungan, dan menulis/berbicara di media cetak maupun elektronik tentang pentingnya perilaku konsumen hijau. Dengan ketiadaan environmental knowledge, environment attitude, recyle behavior, dan political action, maka nilai green consumers' behavior sebesar 3,374. Hal tersebut disebabkan oleh variabel-variabel lain di luar model penelitian ini.

\section{Uji Hipotesis}

\section{Uji t (Uji Pengaruh Parsial)}

Uji pengaruh variabel independen terhadap variabel dependen secara parsial dapat dilakukan dengan melihat nilai signifikansi $(\operatorname{Sig}<0,05)$. Pada Tabel 4 , variabel pengetahuan dan sikap terhadap lingkungan tidak memberikan pengaruh terhadap green consumers' behavior, karena nilai signifikansinya lebih besar dari 0,05. Hal ini dikarenakan masyarakat saat ini lebih tertarik dengan hal-hal yang bersifat aplikatif, lebih memotivasi, dan menginspirasi. Variabel perilaku daur ulang dan tindakan politik memberikan pengaruh signifikan terhadap green consumers' behavior, karena nilai signifikansinya lebih kecil dari 0,05 . Variabel yang paling berpengaruh dominan dan signifikan adalah perilaku daur ulang dan diikuti oleh variabel tindakan politik. Hal tersebut terlihat pada uji t kedua variabel tersebut masingmasing sebesar 0,254, dan 0,250. Beberapa contoh perilaku daur ulang dan tindakan politik pro-lingkungan merupakan bukti nyata yang dapat memotivasi masyarakat untuk berperilaku hijau termasuk dalam perilaku pembelian produk.

\section{Uji F (Uji Pengaruh Simultan)}

Uji $\mathrm{F}$ dilakukan untuk mengetahui ada atau tidaknya pengaruh variabel pengetahuan terhadap lingkungan, sikap terhadap lingkungan, perilaku daur ulang, dan tindakan politik secara simultan terhadap variabel green consumers' behavior. Hasil uji $\mathrm{F}$ dapat dilihat dari nilai signifikansi pada tabel ANOVA (Tabel 5) yang diban- 
dingkan dengan signifikansi 0,05 dalam penelitian ini. Tabel 5 menunjukkan bahwa nilai signifikansi (sig) sebesar 0,000<0,05, sehingga variabel environmental knowledge, environment attitude, recycle behavior, dan political action secara simultan berpengaruh signifikan terhadap variabel green consumers' behavior.

Tabel 5. Hasil Uji F

\begin{tabular}{lcrrrc}
\hline \multicolumn{1}{c}{ Model } & Sum of Squares & $\boldsymbol{d} \boldsymbol{f}$ & Mean Square & t & Sig. \\
\hline Regression & 1049,115 & 4 & 262,279 & 17,715 & $.000^{\mathrm{a}}$ \\
\hline Residual & 1406,525 & 95 & 14,806 & & \\
\hline Total & 2455,640 & 99 & & & \\
\hline
\end{tabular}

Sumber: Data diolah menggunakan SPSS 24,0 (2019).

\section{Koefisien Determinasi $\left(\mathbf{R}^{2}\right)$}

Adjusted $R$-square digunakan untuk melihat persentase sumbangan pengaruh variabel independen secara simultan terhadap variabel dependen. Pada Tabel 6 ditunjukkan nilai Adjusted R-square sebesar 0,403 atau 40,3\%. Persentase tersebut menunjukkan bahwa environmental knowledge, environment attitude, recyle behavior, dan political action pada penelitian ini mampu menjelaskan variasi green consumers' behavior sebesar 40,3\%. Sisanya sebesar 59,7\% merupakan pengaruh dari variabel lain di luar model penelitian ini.

Tabel 6. Hasil Uji Determinasi

Model Summary

\begin{tabular}{ccccc}
\hline Model & $\mathbf{R}$ & R Square & $\begin{array}{c}\text { Adjusted R- } \\
\text { Square }\end{array}$ & $\begin{array}{c}\text { Std. Error of } \\
\text { Estimate }\end{array}$ \\
\hline 1 & 0,654 & 0,427 & 0,403 & 3,848 \\
\hline
\end{tabular}

Sumber: Data diolah menggunakan SPSS 24,0 (2019).

\section{KESIMPULAN DAN SARAN}

Hasil uji pengaruh secara parsial didapatkan bahwa terdapat dua variabel independen yang berpengaruh signifikan terhadap variable dependen green consumers' behavior, sedangkan dua variabel lainnya tidak berpengaruh. Variabel recycle behavior dan political action secara parsial memberikan pengaruh signifikan terhadap green consumers' behavior, sedangkan variabel environmental knowledge dan environment attitude tidak terbukti memberikan pengaruh signifikan terhadap green consumers' behavior. Hal ini dikarenakan masyarakat saat ini lebih tertarik dengan hal-hal yang bersifat aplikatif, lebih memotivasi, dan menginspirasi mereka. Beberapa contoh perilaku daur ulang dan tindakan politik pro-lingkungan merupakan bukti nyata yang dapat memotivasi masyarakat untuk berperilaku hijau termasuk dalam perilaku pembelian produk. Namun, variabel environmental knowledge, environment attitude, recycle behavior, dan political action berpengaruh signifikan terhadap variabel green consumers' behavior secara simultan.

Dari temuan tersebut, maka upaya-upaya peningkatan pada recycle behavior dapat dilakukan melalui pengelolaan program daur ulang secara terbuka, berkelanjutan, dan disosialisasikan secara intensif kepada masyarakat luas melalui media massa, baik cetak 
maupun elektronik untuk meningkatkan green consumers' behavior. Program daur ulang dapat dilakukan dalam bentuk tindakan menggunakan atau memanfaatkannya kembali dengan tujuan lain, memisahkan sampah antara yang dapat didaur ulang dan yang tidak, dan memanfaatkan barang bekas untuk kegiatan bernilai ekonomi. Upaya peningkatan political action dapat dilakukan dengan membentuk forum-forum diskusi yang peduli terhadap isu-isu lingkungan, baik secara formal maupun non-formal, berbagi informasi dengan teman dan saudara terkait produk ramah lingkungan, serta menulis dan berbicara dalam forum diskusi maupun media massa tentang pentingnya perilaku hijau. Upaya ini akan memberikan dampak signifikan terhadap meningkatnya green consumers' behavior melalui dukungan atas tercapainya environmental sustainability. Selain itu, penelitian mendalam terhadap faktor-faktor yang mempengaruhi environmental knowledge dan environment attitude perlu dilakukan lebih lanjut.

\section{DAFTAR REFERENSI}

Adialita, T. (2015). Green Marketing dan Green Consumer Behavior di Indonesia. Jurnal Ekonomi Manajemen dan Akuntansi, 12, 88-106.

Andrew \& Slamet, F. (2013). Pengaruh Environmental Behavior terhadap Green Purchasing Behavior pada Anak Muda Generasi C di Jakarta. The National Conference on Manajemen and Business, 10-20.

Ardhian, D., Adiwibowo, S., \& Wahyuni, E. S. (2016). Peran dan Strategi Organisasi Non Pemerintah dalam Arena NGO's Roles and Strategies in the Environmental Politic Arena. DOI: https://doi.org/10.22500/sodality.v4i3.14429.

Azwar, S. (2010). Sikap Manusia: Teori dan Pengukurannya. Yogyakarta: Pustaka Pelajar Offset.

Baker, J. P., \& Ozaki, R. (2008). Pro-environmental Products: Marketing Influence on Consumer Purchase Decision. Journal of Consumer Marketing, 25(5), 281-293.

Biswas, A., \& Roy, M. (2015). Green Products: An Exploratory Study on the Consumer Behavior in Emerging Economies of the East. Journal of Cleaner Production, 87, 463-468. DOI: https://doi.org/https://doi.org/10.1016/j.jclepro.2014.09.075.

Bohlen, G., Schlegelmilch, B. B., \& Diamantopoulos, A. (1993). Measuring Ecological Concern: A Multi-construct Perspective. Journal of Marketing Management, 9, 415-430. DOI: http://dx.doi.org/10.1080/0267257X.1993.9964250.

Cason, T. N., \& Gangadharan, L. (2002). Environmental Labeling and Incomplete Consumer Information in Laboratory Markets 1. Journal of Environmental Economics and Management, 43, 113-134.

Chan, R. Y. K., Wong, Y. H., \& Leung, T. K. P. (2008). Applying Ethical Concepts to the Study of "Green" Consumer Behavior: An Analysis of Chinese Consumers" Intentions to Bring their Own Shopping Bags. Journal of Business Ethics, 79, 469. DOI: https://doi.org/https://doi.org/10.1007/s10551-007-9410-8.

Colin, A. B., Hammond, F. N., Lamond, J., \& Proverbs, D. G. (2012). Solutions for Climate Change Challenges in the Built Environment (1st ed.). USA: Blackwell.

H'Mida, S., Chavez, E., \& Guindon, C. (2008). Determinant of Pro-environmental Behaviors within Individual Consumers. Journal of Economic Literature (JEL) Classification, 31, 1-12. 
Herri, J. K., \& Putri, N. (2006). Analisis Persepsi Masyarakat terhadap Produk Hijau: Tinjauan Faktor Demografi, Psikologis, Sosial dan Budaya (Kasus Kota Padang). Jurnal Bisnis dan Manajemen, 1, 21-29.

Irawan, A., \& Vianney, A. (2015). Pengaruh Green Practice terhadap Green Consumer Behavior di the Kemangi Restaurant, Hotel Santika Pandegiling Surabaya. Jurnal Hospitality dan Manajemen Jasa, 3(2), 86-101.

Irland, L. C. (1993). Wood Producers Face Green Marketing Era: Environmentally Sound Products. Journal of Wood Technology, 17, 120-134.

Jati, W., \& Waluyo, M. (2012). Green Consumer: Deskripsi Tingkat Kesadaran dan Kepedulian Masyarakat Joglosemar terhadap Kelestarian Lingkungan. Jurnal Dinamika Manajemen, 3(1), 29-39.

Jekria, N., \& Daud, S. (2016). Environmental Concern and Recycling Behavior. Procedia Economics and Finance, 35, 667-673.

Kementerian PUPR (2015). 8 Kementerian akan Tandatangani Revitalisasi Gerakan Nasional Kemitraan Penyelamatan Air. Retrieved March 9, 2020, from https:// www.pu.go.id/berita/view/11540/8-kementerian-akan-tandatangani-revitalisasigerakan-nasional-kemitraan-penyelamatan-air.

Kencana, M. R. B. (2018). Upaya Kementerian PUPR Genjot Pembangunan Berkelanjutan. Retrieved November 4, 2018, from https://www.liputan6.com/bisnis/ $\mathrm{read} / 3683681 /$ upaya-kementerian-pupr-genjot-pembangunan-berkelanjutan.

Lay, C. (2007). Nilai Strategis Isu Lingkungan dalam Politik Indonesia. Jurnal Ilmu Sosial dan Ilmu Politik, 11, 153-172.

Lee, K. (2008). Opportunities for Green Marketing Young Consumers. Marketing Intelligence and Planning, 26(6), 573-586.

Mansaray, A., \& Ajiboye, J. (1998). Environmental Knowledge, Attitudes and Behavior in Dutch Secondary School. Journal of Environmental Education, 30, 4-11.

Neil, C. (2018). The Politics of the Environment: Ideas, Activism, Policy (Third). New York: Cambridge University Press.

Otoritas Jasa Keuangan (2016). UU No 32 Tahun 2009 tentang Perlindungan dan Pengelolaan Lingkungan Hidup. Retrieved March 6, 2020, from https://www.ojk. go.id/sustainable-finance/id/peraturan/undang-undang/Pages/Undang-Undang-No. 32-Tahun-2009-mengenai-Perlindungan-dan-Pengelolaan-LingkunganHidup.aspx.

Permana, E. (2019). Indonesia hasilkan 67 juta ton sampah pada tahun 2019. Retrieved March 9, 2020, from https://www.aa.com.tr/id/headline-hari/indonesia-hasilkan67-juta-ton-sampah-pada-2019/1373712.

Rijati, S., Intan, T., \& Subekti, M. (2017). Sosialisasi Daur Ulang Sampah sebagai Upaya Pengembangan Eko-Budaya di Lingkungan Desa Sayang Jatinangor Kabupaten Sumedang. Jurnal Aplikasi Teknik dan Pengabdian Masyarakat (Jati Emas), 1(2), 29-34.

Rufinaldo, R. K. (2019). Uni Eropa Larang Plastik Sekali Pakai Demi Kebersihan Pantai. Retrieved February 26, 2020, from https://www.aa.com.tr/id/dunia/unieropa-akan-larang-plastik-sekali-pakai-demi-kebersihan-pantai/1484274.

Schultz, P. W., Oskamp, S., \& Mainieri, T. (1995). Who Recycles and When? A Review of Personal and Situational Factors. Journal of Environmental Psychology, 
15 (2), 105-121. DOI: https://doi.org/https://doi.org/10.1016/0272-4944(95) 90019-5.

Septifani, R., Achmadi, F., \& Santoso, I. (2014). Pengaruh Green Marketing, Pengetahuan dan Minat Membeli terhadap Keputusan Pembelian. Jurnal Manajemen Teknologi, 13(2), 201-218.

Setiawan, T. P. (2012). Survei Online Penunjang Penelitian Praktis dan Akademis. Jurnal Semantik, 2, 114-118.

Shamdasani, P., Chon-Lin, G. O., \& Richmond, D. (1993). Exploring Green Consumers in an Oriental Culture. Advances in Consumer Research Journal, 20, 488-493.

Shrum, L. J., McCarty, J. A., \& Lowrey, T. M. (2013). Buyer Characteristics of the Green Consumer and Their Implications for Advertising Strategy. Journal of Advertising, 37-41. DOI: https://doi.org/10.1080/00913367.1995.10673477.

Siringi, R. (2012). Determinants of Green Consumer Behavior of Postgraduate Teachers. IOSR Journal of Business Management (IOSR-JBM), 6(3), 19-25.

Sugiyono (2013). Metode Penelitian Kuantitatif, Kualitatif dan $R \& D$. Bandung: Alfabeta.

Tantawi, P., Shaughnessy, N. O., Gad, K., \& Ragheb, M. A. S. (2009). Green Consciousness of Consumers in a Developing Country: A Study of Egyptian Consumers. 5(1), 29-50. DOI: https://doi.org/https://doi.org/10.7903/cmr.1149.

Tsen, C., Phang, G., Hasan, H., \& Buncha, M. R. (2006). Going Green: A Study of Consumers' Willingness to Pay for Green Products in Kota Kinabalu. International Journal of Business and Society, 7, 40-54.

Widadio, N. A. (2019). Indonesia akan Kurangi 70\% Sampah Plastik pada 2025. Retrieved March 2, 2020, from https://www.aa.com.tr/id/nasional/indonesia-akankurangi-70-persen-sampah-plastik-pada-2025/1671760. 